\title{
Advantages of the outgrowth model for evaluating the implantation competence of blastocysts
}

\author{
Jihyun Kim', Jaewang Lee', Jin Hyun Jun ${ }^{2,3,4}$ \\ ${ }^{1}$ Clinical Medicine Division, Korea Institute of Oriental Medicine, Daejeon; ${ }^{2}$ Department of Biomedical Laboratory Science, College of Health Science, \\ Eulji University, Seongnam; ${ }^{3}$ Department of Senior Healthcare, BK21 Plus Program, Graduate School, Eulji University, Seongnam; ${ }^{4}$ Eulji Medi-Bio \\ Research Institute (EMBRI), Eulji University, Daejeon, Korea
}

The implantation process is highly complex and difficult to mimic in vitro, and a reliable experimental model of implantation has yet to be established. Many researchers have used embryo transfer (ET) to assess implantation potential; however, ET with pseudopregnant mice requires expert surgical skills and numerous sacrificial animals. To overcome those economic and ethical problems, several researchers have tried to use outgrowth models to evaluate the implantation potential of embryos. Many previous studies, as well as our experiments, have found significant correlations between blastocyst outgrowth in vitro and implantation in utero by ET. This review proposes the blastocyst outgrowth model as a possible alternative to animal experimentation involving ET in utero. In particular, the outgrowth model might be a cost- and time-effective alternative method to ET for evaluating the effectiveness of culture conditions or treatments. An advanced outgrowth model and further culture of outgrowth embryos could provide a subtle research model of peri- and postimplantation development, excluding maternal effects, and thereby could facilitate progress in assisted reproductive technologies. Recently, we found that outgrowth embryos secreted extracellular vesicles containing specific microRNAs. The function of microRNAs from outgrowth embryos should be elucidated in further researches.

Keywords: Blastocysts; Extracellular vesicles; Implantation; MicroRNAs; Outgrowth

\section{Introduction}

During mammalian preimplantation development, the fertilized zygote undergoes a continuous series of cleavage steps and a series of morphological changes as it becomes a blastocyst. Prior to attachment and implantation into the maternal uterine endometrium, the blastocyst should hatch from the zona pellucida. Hatched blastocysts are also able to attach onto a culture dish as a form of in vitro implantation through outgrowth [1]. The morphological features of the periimplantation development of mouse embryos to the outgrowth

Received: August 1, 2019 · Revised: December 6, 2019 · Accepted: January 31, 2020 Corresponding author: Jin Hyun Jun

Department of Biomedical Laboratory Science, College of Health Science, Eulji University, B106, Jicheon B/D, 553 Sanseong-daero, Sujeong-gu, Seongnam 13135, Korea

Tel: +82-31-740-7210 Fax:+82-31-740-7351 E-mail:junjh55@hanmail.net

This is an Open Access article distributed under the terms of the Creative Commons Attribution Non-Commercial License (http://creativecommons.org/licenses/by-nc/4.0/) which permits unrestricted non-commercial use, distribution, and reproduction in any medium, provided the original work is properly cited. stage are presented in Figure 1. The implantation process is highly complex and difficult to mimic in vitro, and a reliable research model has yet to be established. Many researchers have used embryo transfer (ET) to assess implantation potential, but ET into pseudopregnant mice requires expert experimental skills and numerous sacrificial animals $[2,3]$. To overcome these economic and ethical problems, several researchers have tried to use outgrowth models to evaluate the implantation potential of embryos. Mammalian embryos, including mouse and human embryos, can attach to an extracellular matrix (ECM) protein-coated culture dish, and develop to peri- and postimplantation stages [4-6].

The initial stages of implantation are poorly understood in humans due to ethical limitations on experimentation. Most of our understanding of blastocyst development and early trophoblast differentiation derives from work with animal models, including non-human primates, livestock, and rodents [7]. The location of the implantation site is difficult to find when in utero biochemical approaches are used due to its small diameter within the relatively large uterine lumen. To 

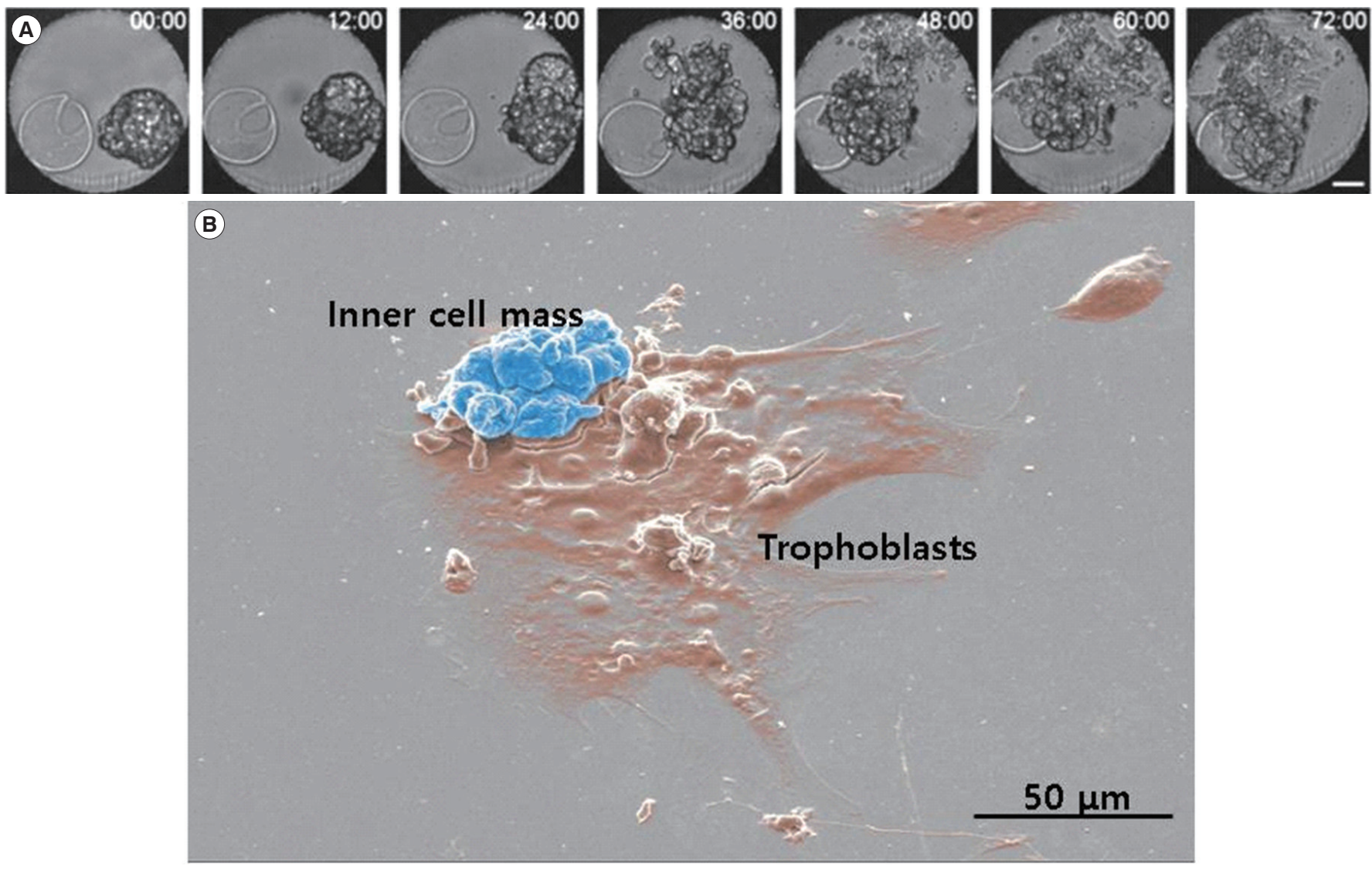

Figure 1. Morphology of hatched blastocyst and the outgrowth stage. (A) Serial images of hatched blastocysts were captured by a time-lapse monitoring system for 3 days. Scale bar, $50 \mu$ m. (B) Scanning electron microscopic image of outgrowth embryos. The cluster of the inner cell mass is presented in blue and the spreading-out trophoblasts are presented in brown.

explore the embryonic side of implantation, in vitro culture of blastocysts has provided a useful experimental model.

The outgrowth model provides an in vitro implantation assay that can be used to characterize the effects of various factors on invasion and proliferation in peri-implantation embryos $[8,9]$. Culturing beyond the blastocyst stage and assessing outgrowth development provide a more sensitive assay for toxins present in in vitro fertilization (IVF) laboratories than traditional quality control assays such human sperm motility and the mouse two-cell embryo assay [10]. However, a more refined approach than the blastocyst outgrowth model is required to investigate the regulation of signaling and adhesion molecules at the apical surface of mural trophoblast cells before they dissociate and migrate outward [11].

The fibronectin-binding assay is ideal for investigating the onset of adhesion at the apical surface of trophoblast cells, since it is performed rapidly and detection does not require any cellular activity beyond ligand binding. Image analysis is effectively used to quantify the spreading area of trophoblasts and the inner cell mass (ICM). The fibronectin-binding assay provides a useful model for assessing the adhesive activity of integrins on the blastocyst surface during peri- implantation development. This model is applicable for a comparative analysis of adhesion throughout development if embryos are treated with various biological molecules and reagents. Some agonists capable of accelerating the rate of blastocyst outgrowth concomitantly shift the onset of fibronectin-binding activity, providing evidence for the physiological relationship between this activity and the adhesion competence of blastocysts [12-15].

In this review, we provide an overview of significant reports regarding historical and functional blastocyst outgrowth models, and suggest that the outgrowth model might be an effective alternative method to ET for analyzing experimental culture conditions or treatments. Furthermore, advanced researches with the blastocyst outgrowth model is proposed to investigate extracellular vesicles (EVs) and microRNAs (miRNAs) as bioactive molecules and biomarkers.

\section{History of research using the outgrowth model of mammalian blastocysts}

We searched for the keywords "blastocyst" and "outgrowth" in the PubMed database, and found that 472 papers had been published. 
Table 1. Summary of early studies (1966-2000) on outgrowth of mammalian blastocysts

\begin{tabular}{|c|c|c|}
\hline Author (year)/journal & $\begin{array}{l}\text { Model } \\
\text { system }\end{array}$ & Significant finding \\
\hline Gwatkin and Meckley (1966)/Ann Med Exp Biol Fenn & Mouse & First report on the attachment and outgrowth of blastocysts in vitro \\
\hline Menke and McLaren (1970)/J Reprod Fertil & Mouse & Carbon dioxide production and trophoblast outgrowth \\
\hline Spindle and Pedersen (1973)/J Exp Zool & Mouse & Fixed nitrogen requirements in outgrowth of blastocysts \\
\hline Dunn (1974)/J Reprod Fertil & Mouse & Inhibition of blastocyst outgrowth in vitro by serum from mice with ascites teratoma \\
\hline Searle et al. (1976)/J Exp Med & Mouse & $\begin{array}{l}\text { Loss of antigen on the trophectoderm at the time of implantation and prevention of } \\
\text { maternal immune rejection during the establishment of the fetal allograft }\end{array}$ \\
\hline Surani (1977)/J Cell Sci & Rat & $\begin{array}{l}\text { Outgrowth of rat blastocysts in vitro with extracellular uterine luminal components, } \\
\text { serum, and hormones }\end{array}$ \\
\hline Shaffer and Wright (1978)/J Anim Sci & Swine & Attachment and trophoblastic outgrowth of swine blastocysts in vitro \\
\hline Atienza-Samols and Sherman (1978)/Dev Biol & Mouse & Outgrowth-promoting factor for the inner cell mass of the mouse blastocyst \\
\hline Surani (1979)/ Cell & Mouse & $\begin{array}{l}\text { Glycoprotein synthesis and inhibition of glycosylation by tunicamycin in mouse } \\
\text { blastocysts outgrowth }\end{array}$ \\
\hline Shalgi and Sherman (1979)/J Exp Zool & Mouse & $\begin{array}{l}\text { Scanning electron microscopy of the surface of normal and implantation-delayed mouse } \\
\text { blastocysts during development and in vitro outgrowth }\end{array}$ \\
\hline Wordinger and McGrath (1979)/Experientia & Mouse & $\begin{array}{l}\text { In vitro hatching and attachment of the mouse blastocyst on the collagen substratum } \\
\text { with serumless medium }\end{array}$ \\
\hline Copp (1980)/Placenta & Field vole & Field vole (Microtus agrestis) outgrowth in vitro for a study of trophoblast cell migration \\
\hline Gonda and Hsu (1980)/J Embryol Exp Morphol & Mouse & $\begin{array}{l}\text { Correlative scanning electron, transmission electron, and light microscopic observation } \\
\text { of mouse blastocyst outgrowth and early-egg-cylinder development in vitro }\end{array}$ \\
\hline Kubo et al. (1981)/J Exp Zool & Mouse & Inhibition of mouse blastocyst attachment and outgrowth by protease inhibitors \\
\hline Van Blerkom and Chavez (1981)/Am J Anat & Mouse & $\begin{array}{l}\text { Morphodynamics of outgrowths of mouse trophoblast in the presence and absence of } \\
\text { a monolayer of uterine epithelium }\end{array}$ \\
\hline Glass et al. (1983)/J Cell Biol & Mouse & $\begin{array}{l}\text { Degradation of extracellular matrix by mouse trophoblast outgrowths in a model for } \\
\text { implantation }\end{array}$ \\
\hline Chavez and McIntyre (1984)/J Reprod Immunol & Mouse & $\begin{array}{l}\text { Abnormalities in mouse peri-implantation blastocysts outgrowth with sera from women } \\
\text { with histories of repeated pregnancy losses }\end{array}$ \\
\hline Armant et al. (1986)/Dev Biol & Mouse & $\begin{array}{l}\text { Promotion effects of fibronectin and laminin on attachment and outgrowth of mouse } \\
\text { blastocysts }\end{array}$ \\
\hline Armant et al. (1986)/Proc Natl Acad Sci U S A & Mouse & $\begin{array}{l}\text { The effect of hexapeptides and the Arg-Gly-Asp tripeptide on attachment and outgrowth } \\
\text { of mouse blastocysts cultured in vitro }\end{array}$ \\
\hline Dealtry and Sellens (1987)/Roux Arch Dev Biol & Mouse & Expression of lectin receptors on peri- and early post-implantation mouse embryos \\
\hline Menino and Williams (1987)/Biol Reprod & Bovine & $\begin{array}{l}\text { Activation of plasminogen by the early bovine embryo in blastocysts and outgrowth } \\
\text { embryos }\end{array}$ \\
\hline Carson et al. (1988)/Dev Biol & Mouse & Collagens and Arg-Gly-Asp supported embryo attachment and outgrowth in vitro \\
\hline Nieder and Caprio (1990)/Mol Reprod Dev & Hamster & In vivo and in vitro development of blastocysts and outgrowth in the Siberian hamster \\
\hline Haimovici et al. (1991)/Biol Reprod & Mouse & $\begin{array}{l}\text { Effects of cytokines from activated lymphocytes and macrophages on blastocyst } \\
\text { implantation and outgrowth in vitro }\end{array}$ \\
\hline Suzuki et al. (1993)/Reprod Fertil Dev & $\begin{array}{l}\text { Guinea } \\
\text { pig }\end{array}$ & $\begin{array}{l}\text { Hatching of the blastocysts and trophoblast outgrowth of guinea pig embryos in } \\
\text { serum-free media }\end{array}$ \\
\hline Yelian et al. (1993)/J Cell Biol & Mouse & $\begin{array}{l}\text { Recombinant entactin promoted mouse primary trophoblast cell adhesion and } \\
\text { migration through the Arg-Gly-Asp recognition sequence }\end{array}$ \\
\hline Haimovici and Anderson (1993)/Biol Reprod & Mouse & $\begin{array}{l}\text { Platelet-derived growth factor and fibroblast growth factor enhanced trophoblast } \\
\text { outgrowth with the fibronectin matrix coating of the culture wells }\end{array}$ \\
\hline Stachecki et al. (1994)/J Reprod Fertil & Mouse & $\begin{array}{l}\text { Mouse blastocyst outgrowth and implantation rates following exposure to ethanol } \\
\text { or A23187 during culture in vitro }\end{array}$ \\
\hline Juneja et al. (1995)/Endocrine & Mouse & $\begin{array}{l}\text { Early embryonic development and trophoblastic outgrowth by activated and inactivated } \\
\text { macrophages }\end{array}$ \\
\hline Bartlett and Menino (1995)/Biol Reprod & Sheep & $\begin{array}{l}\text { Evaluation of extracellular matrices and the plasminogen activator system in sheep inner } \\
\text { cell mass and trophectodermal outgrowth in vitro }\end{array}$ \\
\hline Yelian et al. (1995)/Mol Reprod Dev & Mouse & $\begin{array}{l}\text { Molecular interactions between fibronectin and integrins during mouse blastocyst } \\
\text { outgrowth }\end{array}$ \\
\hline Drakakis et al. (1996)/J Assist Reprod Genet & Mouse & $\begin{array}{l}\text { In vitro development of mouse embryos beyond the blastocyst stage into the hatching } \\
\text { and outgrowth stage using different energy sources }\end{array}$ \\
\hline
\end{tabular}


Table 1. Continued

\begin{tabular}{|c|c|c|}
\hline Author (year)/journal & $\begin{array}{l}\text { Model } \\
\text { system }\end{array}$ & Significant finding \\
\hline Rappolee et al. (1998)/Mol Reprod Dev & Mouse & $\begin{array}{l}\text { Expression of fibroblast growth factor receptors in peri-implantation and outgrowth } \\
\text { mouse embryos }\end{array}$ \\
\hline Shiokawa et al. (1998)/Mol Hum Reprod & Mouse & $\begin{array}{l}\text { Outgrowth of embryos on the decidual cells was inhibited by the addition of herbimycin } \\
\text { A in a dose-dependent manner }\end{array}$ \\
\hline Nowak et al. (1999)/Biol Reprod & Mouse & $\begin{array}{l}\text { Transforming growth factor-beta stimulates mouse blastocyst outgrowth through } \\
\text { a mechanism involving parathyroid hormone-related protein }\end{array}$ \\
\hline Wuu et al. (1999)/Biol Reprod & Mouse & $\begin{array}{l}\text { Tumor necrosis factor-alpha allowed implantation in vitro and decreased the ability } \\
\text { of embryos to differentiate into fetuses after implantation. }\end{array}$ \\
\hline Shiokawa et al. (1999)/Biol Reprod & Mouse & $\begin{array}{l}\text { Functional role of Arg-Gly-Asp-binding sites on beta-1 integrin in embryo implantation } \\
\text { using mouse blastocysts and human decidua }\end{array}$ \\
\hline Mishra and Seshagiri (2000)/Reprod Biomed Online & $\begin{array}{l}\text { Golden } \\
\text { hamster }\end{array}$ & $\begin{array}{l}\text { Heparin binding-epidermal growth factor improved blastocyst hatching and trophoblast } \\
\text { outgrowth in the golden hamster. }\end{array}$ \\
\hline
\end{tabular}

The oldest paper was "Chromosomes of the mouse blastocyst following its attachment and outgrowth in vitro" published by Gwatkin and Meckley in 1966 [16]. This outgrowth model of in vitro implantation was developed by culturing blastocysts under various conditions. After breakdown of the spherical morphology of the blastocyst, trophoblast cells can spread out as a monolayer of cells around the base of the embryo concomitantly with ICM (Figure 1). The outgrowth rate is calculated by the identified number of blastocysts. The grading of outgrowth embryos is determined by the size of the ICM, the number of cells, and the area of trophoblasts, which are spreading out. This in vitro experimental model was developed to overcome the complications of in vivo and ex vivo implantation models, and has been used by several laboratories to evaluate the effects of morphological and biochemical factors on the peri-implantation development of blastocysts [17-19].

Significant papers related to blastocysts and outgrowth published through 2000 are summarized in Table 1. Most of the early papers focused on the outgrowth of mouse blastocysts, but they also encompassed such as rat, bovine, swine, field vole, guinea pig, sheep, hamster, and monkey models, and some were even conducted in humans. In addition, studies reported the morphological changes experienced by blastocysts during outgrowth, the effects of serum and serum-derived components on various conditions, and the effects of inhibiting outgrowth using antibiotic components. In particular, the functional role of the Arg-Gly-Asp (RGD) peptide in the process of implantation and outgrowth was thoroughly studied by the Armant group. The RGD sequence of various ECM proteins intervene in their binding to integrins during the cell adhesion and peri-implantation process [20,21]. The antagonistic peptide Gly-Arg-Gly-Asp-Ser-Pro (GRGDSP) inhibits blastocyst outgrowth on various ECM proteins such as fibronectin, vitronectin, type II collagen, and entactin/nidogen $[4,22,23]$. In the adhesion and invasion of trophoblast cells to the maternal endometrium, the diverse array of adhesive ECM proteins and integrins could provide functional redundancy to increase the likelihood of successful implantation.

Since then, molecular biological methods have been introduced to study the genes that are specifically expressed during outgrowth and their mechanisms of action. Major outgrowth studies from 2000 to the present have focused on evaluating the effects of various amino acids, growth factors, cytokines, and biological and chemical components, and on identifying the mechanisms of action [24-28]. The outgrowth model has also been used in studies to effectively separate and to efficiently produce embryonic stem cells from blastocysts [29-31]. Studies have been conducted to identify and characterize miRNAs and EVs derived from blastocysts and outgrowth embryos in mouse and bovine models, as well as humans. It was shown that the miRNAs and EVs had significant effects on pre- and peri-implantation embryonic development and regulation of the implantation process.

Recent papers have used the mouse blastocyst outgrowth model as an efficient method for assessing the developmental competence of in vitro cultured embryos and peri-implantation viability. Kelley and Gardner [32] published a paper entitled "Individual culture and atmospheric oxygen during culture affect mouse preimplantation embryo metabolism and post-implantation development." They found that peri-implantation development was not affected by individual culture under $5 \%$ oxygen, but under $20 \%$ oxygen, individual culture resulted in smaller outgrowths than embryos that had been cultured in groups, indicating they were less viable. We similarly showed that a dynamic oxygen concentration (decreasing from $5 \%$ to $2 \%$ ) had beneficial effects on mouse pre- and peri-implantation development using an outgrowth model [33].

In a knock-out model in mice, an outgrowth assay was applied to evaluate early embryonic lethality and impaired trophoblast function. The blastocysts from dUTPase knock-out mice could not advance to the outgrowth stage [34]. It was also shown that the med20 
gene is essential for early embryogenesis and regulates nanog expression in mouse blastocysts and outgrowth embryos [35]. Mcrs1 mutant preimplantation embryos exhibited normal morphology at the blastocyst stage, but did not progress to the gastrulation stage, resulting in embryonic loss. Outgrowth assays revealed that the mutant blastocysts did not form a typical ICM colony, the source of embryonic progeny [36].

\section{Developmental competence of mouse blastocysts in outgrowth in vitro and implantation in utero}

The in vitro blastocyst outgrowth model mimics implantation in the uterus in vivo and enables experimental studies on implantation events and mechanisms. This model has also revealed the relationship between metabolism - based on morphokinetic findings of preimplantation embryos - and implantation potential, and has been used as an alternative tool to study trophoblastic invasion and motility [37-40].

Lane and Gardner [41] reported quantitative findings on various parameters of embryo development in vitro, which were correlated with fetal development after the transfer of cultured blastocysts. Morphology, as assessed by blastocyst formation and hatching, was not correlated with subsequent developmental competence. In contrast, significant positive correlations were found between the number of blastocyst cells and the number of ICM cells and subsequent fetal development. Similarly, the attachment ability of blastocysts and ICM outgrowth were also positively correlated with fetal development. Glycolytic activity of blastocysts appeared to be negatively correlated with fetal development after transfer.

In our previous studies, we confirmed a correlation in the developmental competence of preimplantation embryos between blastocyst outgrowth in vitro and implantation in utero [42,43]. We established a novel coculture system with outgrowth and preimplantation embryos, and investigated how this coculture system improved preimplantation and peri-implantation embryonic development both in vitro and in utero. In the coculture system, it was observed that outgrowth embryos secreted EVs by time-lapse monitoring and scanning electron microscopy. Coculture with outgrowth embryos significantly increased the percentage of outgrowth in vitro, which was correlated with implantation rates in utero after ET [42].

A time-lapse monitoring system has been applied to select transferrable embryos and to predict the developmental competence of preimplantation embryos in human IVF-ET programs. We studied blastocyst development and implantation potential in utero based on the third cleavage and compaction times using a mouse model [43]. Our results provided evidence that analyzing morphokinetics by a time-lapse monitoring system may improve the efficacy of selection of transferrable embryos with high implantation potential in human IVF-ET programs. In that study, we found that the times of the third cleavage to the four-cell stage and compaction to the morula stage were useful morphokinetic parameters for predicting the potential of mouse preimplantation embryos to develop into outgrowth in vitro and implantation in utero [43].

\section{Future research using the outgrowth model}

Recently, many studies have investigated the role of EVs in reproductive events, including oogenesis, embryo development and death, oviduct-embryo crosstalk, IVF and others [44-47]. Saadeldin et al. [48] demonstrated that porcine embryos secreted EVs in culture medium that contained mRNA sequences of pluripotency genes. They suggested that EVs carrying embryotrophic signals could act as mediators to improve preimplantation development.

It was proposed that EVs from pre- and peri-implantation embryos might also communicate with maternal immunological factors by presenting and processing antigens [49,50]. EVs were found to contain major histocompatibility complex molecules, cytokines, and miRNAs. Of particular note, HLA-G-positive EVs from healthy term pregnant women's plasma have been found to bind with T lymphocytes and regulate peripheral T lymphocyte STAT3 phosphorylation and activation [51]. As a way to induce a favorable immune system response, EVs from embryos bind to CD8+ and increase the number of interleukin-10+ cells among peripheral CD8+ cells. By producing interleukin 10, an anti-inflammatory cytokine, CD8+ T lymphocytes might alleviate the antigen-induced inflammatory responses. Using immunoelectron microscopy, it was observed that progesterone-induced blocking factor containing EVs from embryos communicated with immune cells [52].

We also isolated and identified EVs and miRNAs from blastocysts and outgrowth embryos [53]. The EVs from outgrowth embryo-conditioned media have rounded membrane structures that range in diameter from 20 to $225 \mathrm{~nm}$. Incubation with EVs improved preimplantation embryonic development by increasing cell proliferation and decreasing apoptosis in blastocysts. Moreover, the implantation rate following ET was significantly higher in EV-supplemented embryos than in the control group [54]. This finding suggests that since EVs contain bioactive molecules from outgrowth embryos, they could enhance embryonic developmental competence and even implantation potential in mice. Giacomini et al. [54] showed that the EVs secreted from cultured embryos not only seemed to improve developmental competence by exchanging embryotrophic messages, but could also send bioactive molecules to the maternal endometrium, supporting a favorable endometrial environment for implantation. 
EVs play a role in cell-to-cell communications because their cargo contains potentially bioactive molecules relevant for physiological responses and pathological conditions. Since miRNAs in EVs have been well characterized, bioinformatic research into the miRNA expression profiles of EVs will be helpful to explore their physiological functions and pathological biomarkers. The numerous suggested biomarkers that could be used to predict the developmental competence of embryos include miRNAs secreted from in vitro cultured preand peri-implantation embryos. In particular, the miRNA profile has been reported to show correlations with fertilization using IVF and intracytoplasmic sperm injection, chromosomal abnormalities of embryos, and pregnancy outcomes [55,56].

Recently, we performed the first profiling study on miRNAs of EVs from blastocysts, non-outgrowth embryos, and outgrowth embryos in mice [57]. A total of 3,163 miRNAs were detected in the blastocysts and outgrowth embryos, and the miRNA expression profiles were significantly different between non-outgrowth and outgrowth embryos. Ten miRNAs (let-7b, miR-23a, miR-27a, miR-92a, miR-183, miR200c, miR-291a, miR-425, miR-429 and miR-652) were identified as significant differentially expressed miRNAs in outgrowth embryos by microarray and in silico analysis. The expression of these miRNAs markedly changed during preimplantation embryo development. In particular, let-7b-5p, miR-200c-3p and miR-23a-3p were significantly upregulated in outgrowth embryos compared with blastocysts and non-outgrowth blastocysts [57]. This study suggested that differentially expressed miRNAs in outgrowth embryos compared with blastocysts and non-outgrowth embryos could be involved in embryo attachment and interactions between the embryo proper and maternal endometrium during the implantation process. We conclude that EVs secreted from outgrowth embryos could improve the developmental competence of in vitro cultured mouse preimplantation embryos. Findings of specific embryotrophic factors and miRNAs from outgrowth embryos might be valuable for advancing reproductive technologies in the future.

\section{Conclusion}

Blastocyst outgrowth has proven to be a useful and efficient model for investigating the adhesion and invasion of trophoblast cells during the implantation process of mammalian embryos. The developmental program of blastocysts and trophoblast cells is regulated by transcripts or proteins produced at an earlier stage by preimplantation embryos. Post-translational modifications of specific proteins, rather than biosynthesis, regulate the onset of trophoblast differentiation in preparation for blastocyst implantation and outgrowth in vitro. The regulation of blastocyst development and outgrowth adhesion independently of gene activation enables cells to adapt to alter- ations in the conditions of in vitro culture. It was recently suggested that spent embryo culture medium metabolites might be related to the ability of blastocysts to undergo outgrowth [58]. In a metabolite analysis of embryo culture medium, non-outgrowth blastocysts that lacked the ability to adhere in vitro had increased requirements for lactate and pyruvate, and showed a significant reduction of the pyruvate-alanine ratio. Thus, it was proposed that the aforementioned metabolites from the spent medium should be further analyzed using proper experimental models to substantiate their potential as biomarkers for predicting the implantation competence of embryos in clinical IVF-ET programs [58].

Supplementation of specific molecules in culture media could improve pre- and peri-implantation development. Treatment with the well-known appetite hormone leptin increased the blastocyst outgrowth rate of ICM during embryonic stem cell derivation [59]. This year, Truong and Gardner [60] reported that addition of a combination of three antioxidants (acetyl-L-carnitine, $\mathrm{N}$-acetyl-L-cysteine, and a-lipoic acid) to vitrification and warming solutions resulted in a significant increase in the outgrowth area, which was correlated with higher fetal weight, crown rump length, and limb development after ET than were found in embryos that did not receive antioxidant treatment.

In many previous studies and our experiments, a significant correlation was found between blastocyst implantation in vitro by an outgrowth assay and implantation in utero by ET. This review suggests that the outgrowth blastocyst assay might be an alternative to animal experimentation involving ET in utero. Using the outgrowth assay could reduce the number of sacrificed animals needed to assess the developmental competence of peri- and postimplantation embryos [61]. Therefore, we suggest that the outgrowth model might be a cost- and time-effective alternative method to ET for evaluating effective culture conditions or treatments. To analyze placental and fetal development in utero, the ET approach will still be required. However, implementing screening tests using the outgrowth model described herein will effectively reduce time, cost, and the number of surgical procedures and sacrifices in animals.

Recently, we found that outgrowth embryos secreted EVs containing specific miRNAs. The function of miRNAs from outgrowth embryos should be elucidated in further research. An advanced outgrowth model and further culture of outgrowth embryos could provide a subtle and valuable research model of peri- and postimplantation development, with implications for progress in assisted reproductive technologies.

\section{Conflict of interest}

Jin Hyun Jun has been an associate editor of Journal of Clinical and 
Experimental Reproductive Medicine since 2018; however, he was not involved in the peer reviewer selection, evaluation, or decision process of this article. No other potential conflicts of interest relevant to this article were reported.

\section{ORCID}

$\begin{array}{ll}\text { Jihyun Kim } & \text { https://orcid.org/0000-0002-2466-1925 } \\ \text { Jaewang Lee } & \text { https://orcid.org/0000-0001-6801-7149 } \\ \text { Jin Hyun Jun } & \text { https://orcid.org/0000-0001-9898-4471 }\end{array}$

\section{Author contributions}

Conceptualization: JHJ. Data curation: JK, JL. Formal analysis: JHJ, JK. Methodology: JK, JL. Visualization: JHJ, JK. Writing-original draft: JK. Writing-review \& editing: JHJ, JL.

\section{References}

1. Armant DR. Blastocyst culture. In: Soares MJ, Hunt JS, editors. Placenta and trophoblast: methods and protocols. Volume I. Totowa: Humana Press; 2006. p. 35-55.

2. Moreno-Moya JM, Ramirez L, Vilella F, Martinez S, Quinonero A, Noguera I, et al. Complete method to obtain, culture, and transfer mouse blastocysts nonsurgically to study implantation and development. Fertil Steril 2014;101:e13.

3. Bin Ali R, van der Ahe F, Braumuller TM, Pritchard C, Krimpenfort P, Berns A, et al. Improved pregnancy and birth rates with routine application of nonsurgical embryo transfer. Transgenic Res 2014; 23:691-5.

4. Armant DR, Kaplan HA, Lennarz WJ. Fibronectin and laminin promote in vitro attachment and outgrowth of mouse blastocysts. Dev Biol 1986;116:519-23.

5. Burrows TD, King A, Loke YW. Expression of integrins by human trophoblast and differential adhesion to laminin or fibronectin. Hum Reprod 1993;8:475-84.

6. Kawamura K, Chen Y, Shu Y, Cheng Y, Qiao J, Behr B, et al. Promotion of human early embryonic development and blastocyst outgrowth in vitro using autocrine/paracrine growth factors. PLoS One 2012;7:e49328.

7. Carson DD, Bagchi I, Dey SK, Enders AC, Fazleabas AT, Lessey BA, et al. Embryo implantation. Dev Biol 2000;223:217-37.

8. Lane M, Gardner DK. Selection of viable mouse blastocysts prior to transfer using a metabolic criterion. Hum Reprod 1996;11:1975-8.

9. Wang J, Mayernik L, Armant DR. Integrin signaling regulates blastocyst adhesion to fibronectin at implantation: intracellular calcium transients and vesicle trafficking in primary trophoblast cells. Dev Biol 2002;245:270-9.

10. Gada RP, Daftary GS, Walker DL, Lacey JM, Matern D, Morbeck DE. Potential of inner cell mass outgrowth and amino acid turnover as markers of quality in the in vitro fertilization laboratory. Fertil Steril 2012;98:863-9.

11. Schultz JF, Armant DR. Beta 1- and beta 3-class integrins mediate fibronectin binding activity at the surface of developing mouse peri-implantation blastocysts: regulation by ligand-induced mobilization of stored receptor. J Biol Chem 1995;270:11522-31.

12. Wang J, Rout UK, Bagchi IC, Armant DR. Expression of calcitonin receptors in mouse preimplantation embryos and their function in the regulation of blastocyst differentiation by calcitonin. Development 1998;125:4293-302.

13. Wang J, Paria BC, Dey SK, Armant DR. Stage-specific excitation of cannabinoid receptor exhibits differential effects on mouse embryonic development. Biol Reprod 1999;60:839-44.

14. Wang J, Mayernik L, Schultz JF, Armant DR. Acceleration of trophoblast differentiation by heparin-binding EGF-like growth factor is dependent on the stage-specific activation of calcium influx by ErbB receptors in developing mouse blastocysts. Development 2000;127:33-44.

15. Wang J, Armant DR. Integrin-mediated adhesion and signaling during blastocyst implantation. Cells Tissues Organs 2002;172: 190-201.

16. Gwatkin RB, Meckley PE. Chromosomes of the mouse blastocyst following its attachment and outgrowth in vitro. Ann Med Exp Biol Fenn 1966;44:125-7.

17. Spindle Al, Pedersen RA. Hatching, attachment, and outgrowth of mouse blastocysts in vitro: fixed nitrogen requirements. J Exp Zool 1973;186:305-18.

18. Sherman MI, Atienza-Samols SB. In vitro studies on the surface adhesiveness of mouse blastocysts. In: Ludwig H, Tauber PF, editors. Human fertilization. New York: Georg Thieme Publishers; 1978. p. 179-83.

19. Surani MA. Glycoprotein synthesis and inhibition of glycosylation by tunicamycin in preimplantation mouse embryos: compaction and trophoblast adhesion. Cell 1979;18:217-27.

20. Plow EF, Haas TA, Zhang L, Loftus J, Smith JW. Ligand binding to integrins. J Biol Chem 2000;275:21785-8.

21. Ruoslahti E. RGD and other recognition sequences for integrins. Annu Rev Cell Dev Biol 1996;12:697-715.

22. Armant DR, Kaplan HA, Mover H, Lennarz WJ. The effect of hexapeptides on attachment and outgrowth of mouse blastocysts cultured in vitro: evidence for the involvement of the cell recognition tripeptide Arg-Gly-Asp. Proc Natl Acad Sci U S A 1986;83: 6751-5.

23. Yelian FD, Edgeworth NA, Dong LJ, Chung AE, Armant DR. Re- 
combinant entactin promotes mouse primary trophoblast cell adhesion and migration through the Arg-Gly-Asp (RGD) recognition sequence. J Cell Biol 1993;121:923-9.

24. Martin PM, Sutherland AE. Exogenous amino acids regulate trophectoderm differentiation in the mouse blastocyst through an mTOR-dependent pathway. Dev Biol 2001;240:182-93.

25. Seshagiri PB, Mishra A, Ramesh G, Rao RP. Regulation of peri-attachment embryo development in the golden hamster: role of growth factors. J Reprod Immunol 2002;53:203-13.

26. Martin PM, Sutherland AE, Van Winkle L. Amino acid transport regulates blastocyst implantation. Biol Reprod 2003;69:1101-8.

27. Whiteside EJ, Boucaut KJ, Teh A, Garcia-Aragon J, Harvey MB, Herington AC. Elevated concentration of TNF-alpha induces trophoblast differentiation in mouse blastocyst outgrowths. Cell Tissue Res 2003;314:275-80.

28. Kawamura K, Kawamura N, Sato W, Fukuda J, Kumagai J, Tanaka T. Brain-derived neurotrophic factor promotes implantation and subsequent placental development by stimulating trophoblast cell growth and survival. Endocrinology 2009;150:3774-82.

29. Lorthongpanich C, Yang SH, Piotrowska-Nitsche K, Parnpai R, Chan AW. Development of single mouse blastomeres into blastocysts, outgrowths and the establishment of embryonic stem cells. Reproduction 2008;135:805-13.

30. Doungpunta J, Santhi A, Sathanawongs A, Jarujinda Y, Oranratnachai A. Fivefold increase in derivation rates of mouse embryonic stem cells after supplementation of the media with multiple factors. Theriogenology 2009;72:232-42.

31. Omidi M, Aflatoonian B, Tahajjodi SS, Khalili MA. Attempts for generation of embryonic stem cells from human embryos following in vitro embryo twinning. Stem Cells Dev 2019;28:303-9.

32. Kelley RL, Gardner DK. Individual culture and atmospheric oxygen during culture affect mouse preimplantation embryo metabolism and post-implantation development. Reprod Biomed Online 2019;39:3-18.

33. Lee SC, Seo HC, Lee J, Jun JH, Choi KW. Effects of dynamic oxygen concentrations on the development of mouse pre- and peri-implantation embryos using a double-channel gas supply incubator system. Clin Exp Reprod Med 2019;46:189-96.

34. Palinkas HL, Racz GA, Gal Z, Hoffmann OI, Tihanyi G, Rona G, et al. CRISPR/Cas9-mediated knock-out of dUTPase in mice leads to early embryonic lethality. Biomolecules 2019;9:136.

35. Cui W, Marcho C, Wang Y, Degani R, Golan M, Tremblay KD, et al. MED20 is essential for early embryogenesis and regulates NANOG expression. Reproduction 2019;157:215-22.

36. Cui W, Cheong A, Wang Y, Tsuchida Y, Liu Y, Tremblay KD, et al. MCRS1 is essential for epiblast development during early mouse embryogenesis. Reproduction 2020;159:1-13.
37. Lee YS, Thouas GA, Gardner DK. Developmental kinetics of cleavage stage mouse embryos are related to their subsequent carbohydrate and amino acid utilization at the blastocyst stage. Hum Reprod 2015;30:543-52.

38. Gonzalez IM, Martin PM, Burdsal C, Sloan JL, Mager S, Harris T, et al. Leucine and arginine regulate trophoblast motility through mTOR-dependent and independent pathways in the preimplantation mouse embryo. Dev Biol 2012;361:286-300.

39. Gangloff YG, Mueller M, Dann SG, Svoboda P, Sticker M, Spetz JF, et al. Disruption of the mouse mTOR gene leads to early postimplantation lethality and prohibits embryonic stem cell development. Mol Cell Biol 2004;24:9508-16.

40. Nakayama T, Fujiwara H, Maeda M, Inoue T, Yoshioka S, Mori T, et al. Human peripheral blood mononuclear cells (PBMC) in early pregnancy promote embryo invasion in vitro: HCG enhances the effects of PBMC. Hum Reprod 2002;17:207-12.

41. Lane M, Gardner DK. Differential regulation of mouse embryo development and viability by amino acids. J Reprod Fertil 1997; 109:153-64.

42. Kim J, Lee J, Kim SH, Jun JH. Coculture of preimplantation embryos with outgrowth embryos improves embryonic developmental competence in mice. Reprod Sci 2016;23:913-23.

43. Kim J, Kim SH, Jun JH. Prediction of blastocyst development and implantation potential in utero based on the third cleavage and compaction times in mouse pre-implantation embryos. J Reprod Dev 2017;63:117-25.

44. Andronico F, Battaglia R, Ragusa M, Barbagallo D, Purrello M, Di Pietro C. Extracellular vesicles in human oogenesis and implantation. Int J Mol Sci 2019;20:2162.

45. Rodrigues TA, Tuna KM, Alli AA, Tribulo P, Hansen PJ, Koh J, et al. Follicular fluid exosomes act on the bovine oocyte to improve oocyte competence to support development and survival to heat shock. Reprod Fertil Dev 2019;31:888-97.

46. Kurian NK, Modi D. Extracellular vesicle mediated embryo-endometrial cross talk during implantation and in pregnancy. J Assist Reprod Genet 2019;36:189-98.

47. Lv C, Yu WX, Wang Y, Yi DJ, Zeng MH, Xiao HM. MiR-21 in extracellular vesicles contributes to the growth of fertilized eggs and embryo development in mice. Biosci Rep 2018;38:BSR20180036.

48. Saadeldin IM, Kim SJ, Choi YB, Lee BC. Improvement of cloned embryos development by co-culturing with parthenotes: a possible role of exosomes/microvesicles for embryos paracrine communication. Cell Reprogram 2014;16:223-34.

49. Montecalvo A, Shufesky WJ, Stolz DB, Sullivan MG, Wang Z, Divito $\mathrm{SJ}$, et al. Exosomes as a short-range mechanism to spread alloantigen between dendritic cells during T cell allorecognition. J Immunol 2008;180:3081-90. 
50. Raposo G, Nijman HW, Stoorvogel W, Liejendekker R, Harding CV, Melief CJ, et al. B lymphocytes secrete antigen-presenting vesicles. J Exp Med 1996;183:1161-72.

51. Pap E, Pallinger E, Falus A, Kiss AA, Kittel A, Kovacs $P$, et al. T lymphocytes are targets for platelet- and trophoblast-derived microvesicles during pregnancy. Placenta 2008;29:826-32.

52. Pallinger E, Bognar Z, Bogdan A, Csabai T, Abraham H, SzekeresBartho J. PIBF+ extracellular vesicles from mouse embryos affect IL-10 production by CD8+ cells. Sci Rep 2018;8:4662.

53. Kim J, Lee J, Lee TB, Jun JH. Embryotrophic effects of extracellular vesicles derived from outgrowth embryos in pre- and periimplantation embryonic development in mice. Mol Reprod Dev 2019;86:187-96.

54. Giacomini E, Vago R, Sanchez AM, Podini P, Zarovni N, Murdica V, et al. Secretome of in vitro cultured human embryos contains extracellular vesicles that are uptaken by the maternal side. Sci Rep 2017;7:5210.

55. Rosenbluth EM, Shelton DN, Wells LM, Sparks AE, Van Voorhis BJ. Human embryos secrete microRNAs into culture media: a potential biomarker for implantation. Fertil Steril 2014;101:1493500.

56. Battaglia R, Palini S, Vento ME, La Ferlita A, Lo Faro MJ, Caroppo E, et al. Identification of extracellular vesicles and characterization of miRNA expression profiles in human blastocoel fluid. Sci Rep 2019;9:84.

57. Kim J, Lee J, Jun JH. Identification of differentially expressed microRNAs in outgrowth embryos compared with blastocysts and non-outgrowth embryos in mice. Reprod Fertil Dev 2019;31:64557.

58. D'Souza F, Uppangala S, Asampille G, Salian SR, Kalthur G, Talevi $\mathrm{R}$, et al. Spent embryo culture medium metabolites are related to the in vitro attachment ability of blastocysts. Sci Rep 2018;8: 17025.

59. Taskin AC, Kocabay A, Ebrahimi A, Karahuseyinoglu S, Sahin GN, Ozcimen $B$, et al. Leptin treatment of in vitro cultured embryos increases outgrowth rate of inner cell mass during embryonic stem cell derivation. In Vitro Cell Dev Biol Anim 2019;55:473-81.

60. Truong TT, Gardner DK. Antioxidants increase blastocyst cryosurvival and viability post-vitrification. Hum Reprod 2020;35:1223.

61. Binder NK, Hannan NJ, Gardner DK. In vitro embryo outgrowth is a bioassay of in vivo embryo implantation and development. Asian Pac J Reprod 2015;4:240-1. 